depth with the electron microscope. Again, a little editing would have improved this article no end.

Incidentally, although Lumsden suggests the contrary, Cavenagh has recently given good evidence for mitosis in astrocytes in vivo in adult mammals. And to subscribe to the view that the astrocyte forms the extracellular compartment in the brain (see later) is yet another example of Lumsden writing out of his depth.

Peter's article on the morphology of axons of the central nervous system is an authoritative and well presented account, although one has to turn to his and other more recent work for a clear description of the linked microtubules found in axon hillocks.

Lampert gives a brief but useful account of myelin changes in the central nervous system, which is relevant to problems of demyelinating diseases.

Ramón-Moliner's chapter on the morphology of dendrites follows. It is a long and interesting account based on Golgi preparations. Comparative studies are restricted to vertebrates-a section, however brief, on comparison with invertebrate dendritic organization would have been most illuminating. There is now a considerable electron microscope literature on the synaptic organization of different sorts of dendrites, which this author should have used. Dendritic and synaptic organization are surely inseparable.

Cole gives a rather limited account of retrograde degeneration in the central nervous system. Fine structure is hardly dealt with and important questions, for example, the absence of chromatolysis following section of proximal stumps of dorsal root ganglia, are sidestepped.

Glees and Meller review the morphology of neuroglia but omit the microglia and other important information, such as the use of tight junctions as criteria for recognizing glial processes.

Elfvin follows with a useful account of the fine structure of nerve fibres, mostly authoritative, but he still thinks that the inside of the Schwann cell might represent the "sodium space" outside the axon. Bare axons are well known in the peripheral nervous system and occur in enormous numbers in the central nervous system, where they lie against each other in bundles with no intervening glia. This, and the recent work of Kuffler and his group, leaves little doubt that the sodium space is normally an extracellular compartment around the neurone.

Shantha and Bourne develop the concept of the perineurium as a specialized epithelium. The article is most helpful in tidying up the rather vague concepts of nerve sheaths that most of us have. Unfortunately, the sheaths of Key and Retzius and Plenk and Laidlaw are not clearly described (see Thomas, P. K., J. Anat., $97,35 ; 1963)$.

The final article is an excellent account of neurosecretion by Hofer. One clear diagram or electron micrograph of an ending showing its membrane and distribution of its content of granular and agranular vesicles would have helped though.

In a book of this nature one would have expected a section on synaptic morphology, but there isn't one.

E. G. Gray

\section{KINDNESS TO PLANTS}

\section{Elements of Biological Science}

By William T. Keeton. Pp. xiii +582 . (Norton: New York, 1969.) \$7.95.

THIs book is an abridged version of an earlier text and makes no claim to be comprehensive. It is intended as basic reading for American college students following either a condensed or extended course. It is adequately documented and includes generous, well classified recom- mendations for further reading. There is a very full and useful index and a short glossary.

After a brief unresolved opening discussion on the nature of life and on the nature of science and scientific method, and enough introductory chemistry to make life processes intelligible, the author mentions Darwin's evolutionary hypothesis as the fundamental unifying concept of biology. Subsequent chapters deal clearly and systematically with cells as units of structure and function, energy, flow, nutrition, gaseous exchange, internal transport and body fluids, chemical and nervous control systems, sensory receptors and effectors. A lucid account of current ideas about behaviour and communication follows, and the section "Perpetuation" covers reproduction, inheritance and development. Concluding chapters on population and communities bring the reader back full circle through the origin and diversity of existing plant and animal forms to a more detailed and cogent consideration of evolution.

Your botanist reviewer could not but be mollified by the author's just claim that he had "tried hard to avoid slighting the plants". Indeed, his treatment is refreshingly logical in sequence and biological in outlook. He takes the reader on a reasonably full, sequential conducted tour of the subject. $\mathrm{He}$ interprets all topics in the light of modern evolutionary theory, discusses the problems facing all living things and examines the solutions of those problems in representative organisms.

As an introduction for the intelligent layman or a synoptic refresher course for the intermediate student the work has much to commend it. It is well and liberally illustrated throughout by outline diagrams and photomicrographs.

E. J. Vinnicombe

\section{FISH PERIODICAL}

\section{Journal of Fish Biology}

Vol. 1, No. 1. Pp. 84. (Academic Press: London. Published quarterly for the Fisheries Society of the British Isles, January 1969.) Annual subscription 105s; \$14.50.

MANY fisheries biologists were, no doubt, interested to see the first issue of the Journal of Fish Biology which is being published quarterly for the Fisheries Society of the British Isles. The society was started in October 1967 "to promote a liaison between workers in the field of fish biology".

The editor and publishers are to be congratulated on the appearance of this first issue. The layout and arrangement have been well planned, the line diagrams and graphs are well reproduced and there is a generous allowance of plates (one in colour) which are generally well up to the standard of the other illustrations.

There are nine papers in this first issue, all concerned with freshwater fish, ehiefly on feeding relationships, disease and parasites, though other papers deal with the mapping of the distribution of freshwater fish, the toxicity of ammonia, phenol and zine to rainbow trout, aquatic weed control using grass carp and a note on the photography of fish scales. As one of the aims of the Fisheries Society is to "support all branches of fish biology and fishery sciences" it is perhaps unfortunate that this first issue should have been entirely freshwater in its scope, but the value of a journal cannot be assessed accurately on the basis of one issue and the balance may well be redressed in later issues.

As the dissemination of information on fishery management is another of the society's stated aims it is hoped that future issues of this journal will include papers within this field. A great deal of interesting work on fishery management is now being carried out, particularly by the staffs of the river authorities in England and Wales, and this journal would seem to be a useful means of 